\title{
Laboratory Study on Comparison of the Scour Depth and Scour Length of Groundsill with the Opening and Groundsill without the Opening
}

\author{
Ani Hairani \\ Department of Civil Engineering, Universitas Muhammadiyah Yogyakarta, Bantul, INDONESIA \\ anihairani@umy.ac.id \\ Djoko Legono \\ Department of Civil and Environmental Engineering, Universitas Gadjah Mada, Yogyakarta, INDONESIA \\ djokolegono@ugm.ac.id
}

\begin{abstract}
River bed control structure what so called groundsill or bottom sill is built for controlling a river bed to remain stable against degradation. Unlike other river obstacles, the presence of groundsill might cause sediment retention upstream of the structure; hence it reduces the supply of sediment to the downstream part of the river. At some extent, the above situation might create unexpected negative impact, not only cease the sediment migration but also disable fish migration, as well as the utilization of river for navigation. This paper presents the hydraulic investigation on various models of groundsill, i.e. groundsill without the opening and groundsill with a certain type of the opening. Series of laboratory experiments were conducted on an open channel flow of $0.75 \mathrm{~m}$ width and longitudinal slope of $0.05 \%$. There were two types of groundsill, i.e. groundsill without the opening with $0.75 \mathrm{~m}$ width and $0.05 \mathrm{~m}$ height, and groundsill with the opening of $0.39 \mathrm{~m}$ width and $0.005 \mathrm{~m}$ height of crest at the opening and $0.05 \mathrm{~m}$ at the wings. Various flow rates were then introduced, necessary data were taken, and the hydraulic phenomena were studied. The results showed that groundsill without the opening produced non-dimensional (relative to the channel width) scour depth of 0.036 , and scour length of 0.253 . Groundsill with the opening produced scour depth of 0.013 and 0.024 near the downstream end of the wing section and the opening respectively. The scour length of the groundsill with the opening is 0.080 and 0.293 near the downstream end of the wing section and the opening section respectively. Moreover, it can be noted that the presence of the scour depth and scour length of the groundsill with the opening was generally much smaller rather than that of groundsill without the opening. The above results give the evidence that groundsill with the opening is much friendlier and also more suitable for the environment needs.
\end{abstract}

Keywords: control structure, environmentally sound, groundsill, hydraulic phenomenon.

\section{INTRODUCTION}

The river is water resource that has great benefit for life. Not only as natural drainage, but also used for drinking water, the habitat of water biotas, and transportation (Sosrodarsono, 1985). Due to these important roles, environmental preservation and restoration are highly required to keep it being well functioned. In general, the purposes of preservation and restoration are to prevent flood, sedimentation, and to maintain the river stream from incriminating horizontal or vertical alignment changes. One of the flow stabilization work is by constructing groundsill which belongs to sediment control structure to maintain the river bed elevation from degradation process. River as natural drainage has stream and bed slope characteristics which may easily change. Construction of the river structure, and human activities that may cause flow or bed slope alteration give impact to the changes of its length and bed slope. Changes in the flow or bed slope induce the changes of the flow tractive force, which then disturbs the river bed balance. It changes until a new equilibrium condition has met. The groundsill presence is expected to maintain the river bed elevation on a certain height, yet it also can bring negative effects including the decreasing of sediment supply from the upstream, and the degradation in the river bed on the downstream of the groundsill. At the dry season, when the water elevation is very low, and so do the sediment supply, the existence of groundsill is considered to be less environment-friendly. Therefore, groundsill should be designed in such condition that negative impacts are minimized. It can be achieved by making an opening system on the groundsill (Novriska, 2000). The aforementioned opening is expected to still be used for boat traffic, also the possibility of water biota that migrates along the river flow. With the opening in the middle part of the groundsill, the balance between supply and withdrawal of the sediment on the river upstream is possible. Furthermore, studies on the hydraulic of groundsill structure type are needed to study the scour pattern after the groundsill existed, with variations of discharge and shape of the groundsill, and to solve the complexity of the hydraulic characteristics on the groundsill by 
comparing the result between the approached theory and laboratory investigation.

\section{LITERATURE REVIEW AND THEORETICAL BASIS}

Erosion and deposition process on the river are generally happened due to changes in the flow pattern. It is caused by the existence of obstacles in the river flow in the mean of river construction, such as bridge pillar and abutment, river curb, groundsill, water gate, and so forth. According to Elsebaie (2013), scouring may be defined as the removal of material around or near structures located in flowing water. Such phenomenon may, in turn, cause the lowering of the riverbed level by water erosions such that there is a tendency to expose the foundations of structures. The lowering of the river bed level as caused by the local scour can progressively undermine the foundation the structure leading to failure. The complete protection against scour is usually too expensive, generally, the maximum scour depth has to be estimated to consider the further protection design against the risk of the failure (Khwairakpam and Mazumdar, 2009). River construction such as water gate is deemed to be able to change the geometry of the stream flow and the flow pattern which leads to local scouring on the downstream (Raudkivi, 1967). This process takes place alongside the river for several kilometers and for a long time (De Vries, 1975 recited in Hoffman 1977). Different type of scouring as given by Raudkivi and Ettema (1982) in (1990) are as follows:

a) General scour in the river channel does not relate to the presence of the hydraulic structure on the river.

b) Local scour is caused by the narrowing of river channel; the flow becomes centralized.

c) Local scour in the vicinity of the structure is affected by the local flow pattern.

These three scouring events may occur simultaneously, yet in different locations. The scouring type 2 and 3 are classified into clean water scour and live bed scour. Clean water scour occurs when the river bed materials in the upstream of the hydraulic structure are in equilibrium condition (no material transported). Live bed scours is associated with bed material transport.

According to Laursen (1952) recited in Legono (1990), the natural scouring is characterized as follow:

a) The size of scouring is equal to the difference of the amount of sediment materials conveyed to the scouring area and the materials coming out of the scouring area. b) The amount of scouring is decreased if the wetted area in the scouring area is increased.

c) There is such circumstance in which the scouring amount is the maximum and being asymptotic with time.

The equation of maximum local scour in the downstream threshold by Lacey is as follows:

$$
\begin{aligned}
& d s=1,35\left(\frac{q 2}{f}\right)^{1 / 3} \\
& f=1,76 \sqrt{d_{50}}
\end{aligned}
$$

where $d s$ is scour depth, calculated from the original bed level on the downstream $(\mathrm{m}), d_{50}$ represents average particle size or median grain diameter, $q$ is flooded discharge per river width unit $\left(\mathrm{m}^{3} / \mathrm{s}\right)$, and $f$ is silt factor (the erodibility of the bed material).

Considering the uncertainty value of silt factor in Equation (2) so that it is necessary to validate the scour value with the model test. With the increase of $d_{50}$, the silt factor is increased as well, while the scour depth is decreased. In practice, it is often found that the river bed grain size is generally not uniform. This nonuniformity leads to a physical phenomenon in which the scour depth value in the river bed with non-uniform grain size is lower than the river bed with uniform grain size. The reliability of Equation (1) is also influenced by the flow discharge per river width unit $(q)$. In the reality, $q$ is never uniform since the river flow generally has more than two dimensions. In terms of practice, the recommended way to estimate the scour depth is by investigating the subgrade stratigraphy, or the density value, and so on. Some researchers mentioned that the lowest level of the latest scour could be discovered by the difference of density on river bed channel. However, it should be noted that those all are on the range of uncertainty. Lacey stated that the average flow depth is influenced by the flow discharge and the silt factor, which was written into the following equation:

$$
d_{m}=0.47\left(\frac{Q}{f}\right)^{1 / 3}
$$

Where $d_{m}$ is average flow depth (m), $Q$ is flow discharge $\left(\mathrm{m}^{3} / \mathrm{second}\right)$, and $f$ is silt factor which is listed in Table 1.

To estimate the scour depth, the $d_{m}$ value on the Equation (3) needs to be multiplied with a coefficient as the function of river shapes (see in Table 2). The Equation (3) is derived from Equation (1) so that the 
regime theory still dominates the prediction result of scour depth.

Table 1. Silt Factor values for various grain (Neill, 1975)

\begin{tabular}{ll}
\hline Grain diameter $(\mathrm{mm})$ & Silt Factor value $(f)$ \\
\hline 0.08 & 0.50 \\
0.16 & 0.70 \\
0.23 & 0.85 \\
0.50 & 1.00 \\
0.72 & 1.50 \\
1.00 & 1.75 \\
1.30 & 2.00 \\
\hline
\end{tabular}

Table 2. Multiplying factor according to river shapes (Neill, 1975)

\begin{tabular}{ll}
\hline River shape & Multiplying factor \\
\hline Straight & 1.25 \\
Medium curve & 1.50 \\
Strong curve & 1.75 \\
Sudden curve & 2.00 \\
End of pillar & 2.00 \\
Along the pillar & 2.25 \\
End of crib & 2.75 \\
\hline
\end{tabular}

The general instructions that can be used for estimating the scour depth are not available since the information on scour depth recorded in the field is still limited. It is recommended to conduct scour depth estimation by recording the real event on the field. Laboratory experiment on investigating movable bed model shows phenomenon which is close to the real condition. According to Blench (in Neill, 1975), if there is no available instruction, scour depth estimation could also be approached with these following procedures:

a) Estimate the flow discharge $q_{f}$ ( $\mathrm{ft}^{3} /$ second $)$ which is multiplication between flow velocity and average flow depth. It should be noted it used the assumption of a wide profile river.

b) Calculate the regime depth $d_{f o}$ in feet considering no sediment supply according to Equation (4):

$$
d_{f o}=\left(\frac{q_{f}^{2}}{F_{b o}}\right)^{1 / 3}
$$

where $F_{b o}$ is zero bed factor according to Blench (see Figure 1).

c) Estimate the maximum scour depth, which is multiplication between $z x d_{f o}$, whereas $z$ is a factor according to Table 3 .

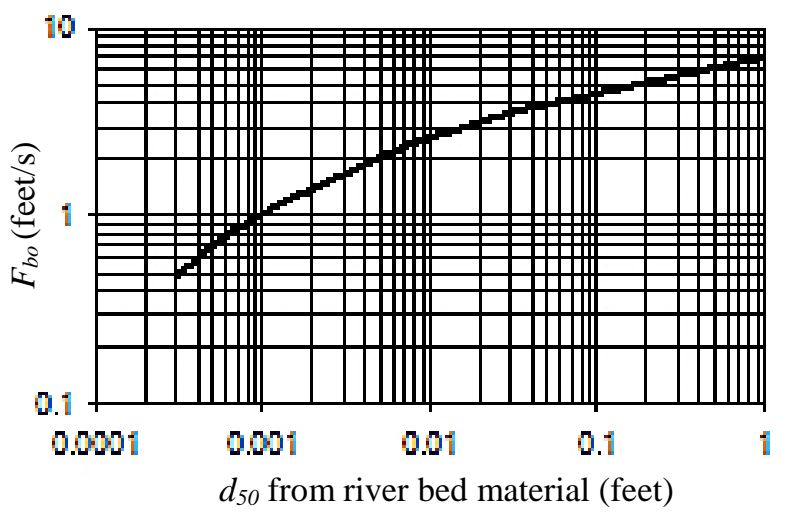

Figure 1. $F_{b o}$ value as $d_{50}$ function (Neill, 1975).

Table 3. Factor of $z$ according to river shapes (Neill, 1975)

\begin{tabular}{ll}
\hline River shape & $z$ \\
\hline Near the groin & $2.0-2.75$ \\
Flow is near the curving toe & 2.25 \\
Flow is aligned with the toe & $1.5-2.0$ \\
\hline
\end{tabular}

\section{LABORATORY EXPERIMENT}

Considering the complexity of scouring phenomenon, the understanding of scouring behavior in the downstream of groundsill was studied through a couple series of laboratory experiments. Several preparations made in part of the investigation related to the preparation of the open channel model, groundsill model, also other materials/equipment.

\subsection{Physical Model}

The model has closed circuit flow as shown in Figure 2 , with a longitudinal slope of 0.0005 and channel width of $0.75 \mathrm{~m}$. It used sand materials with specific physical parameters as bed river materials. On the channel model, a flow discharge measurement facility (Thomson type) was built. It was placed in the first part of the open channel. Close to the flow discharge measurement, downstream side, stilling basin was placed; while on the downstream side, water level elevation controller was placed.

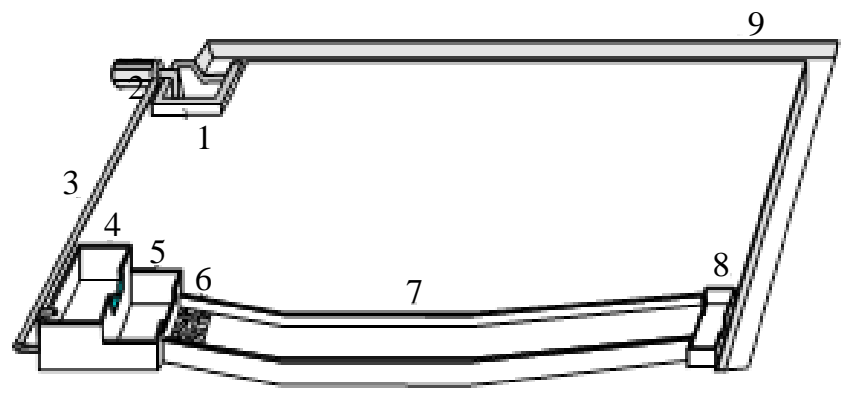

Figure 2. Sketch of Laboratory Experiment.

Description: 1.Reservoir, 2. Pump, 3. Water conveyor to Thomson tank, 4. Thomson tank type, 5. Fore Bay, 
6. End sill tank, 7. Channel, 8. Deposit trap tank, 9. Tailrace

\subsection{Groundsill Model}

There were two groundsill models those have been studied, i.e. groundsill without the opening and groundsill with the opening. Figure 3 and 4 show the sketch of Groundsill Type I (groundsill without opening) and Groundsill Type II (groundsill with the opening) respectively. Measurement of the depth of scouring was carried out by the use of the tape measuring equipment. The term of environmental friendly was defined as it allows water passing through the groundsill in low discharge condition.

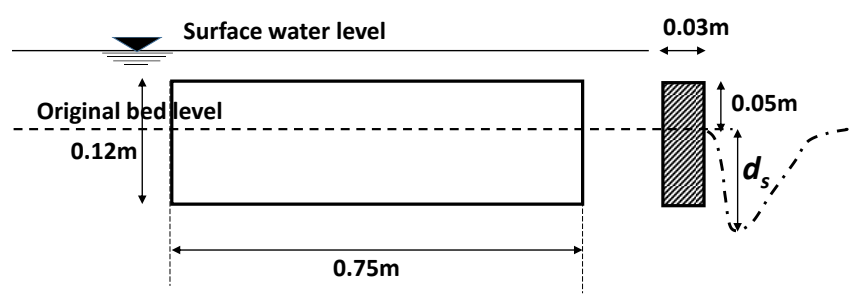

Figure 3. Groundsill Type I (without opening).

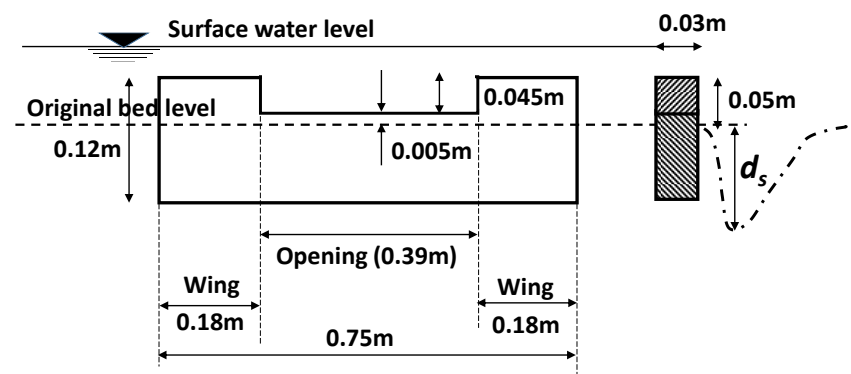

Figure 4. Groundsill Type II (opening type).

Series of groundsill comprising of groundsill without the opening and groundsill with the opening was introduced in every run of various discharges. The groundsill model was placed on the channel section that was relatively straight and was serially mounted with a certain distance (Figure 5).

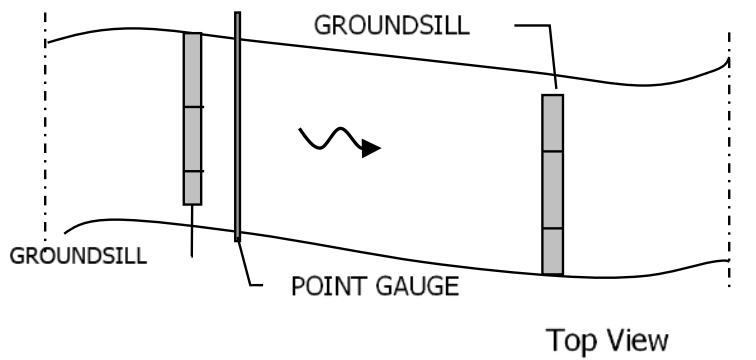

Figure 5. Groundsill mounting on channel model

\subsection{Material and Equipment}

The grain size distribution of sand material used as moveable bed materials was shown in Figure 6 . Another equipment was also used, such as the Thomson discharge controller, pump, as well as some tools for recording the experiment results while running, such as stop watch, point gauge, ruler, and so forth.

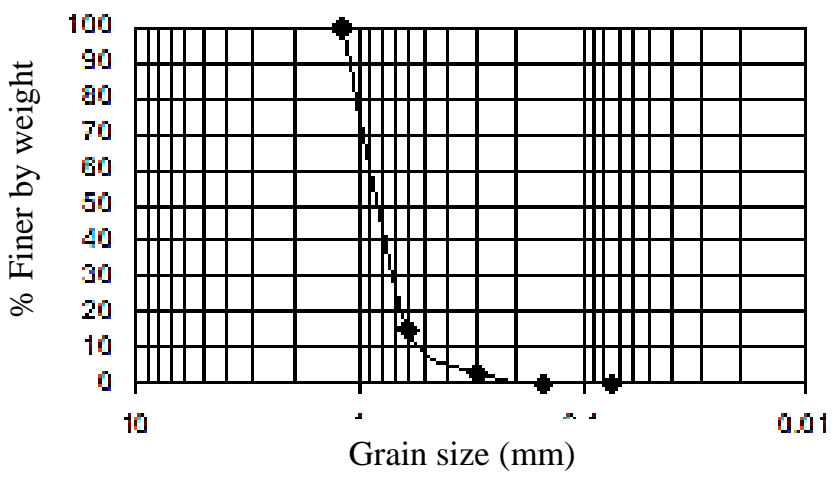

Figure 6. Distribution curve on river bed material grain size

To estimate the effect of non-uniform material, a coefficient factor was used to theoretically evaluate the scour depth equation. Several literatures mentioned that other than $d_{50}$, the $d_{84.1}$, and $d_{15.9}$ could be used for the non-uniformity grain levels (Vanoni, 1975). For practical reason, the $d_{84.1}$ value could be considered equal to $d_{84}$ value, while the $d_{15.9}$ value could be considered equal to $d_{16}$. Kinori mentioned in Vanoni (1975) that the non-uniformity level of grain sizes could be stated in the Geometric Standard Deviation $(\sigma g)$ and Gradation Coefficient $(G)$ as follows:

$$
\begin{aligned}
& \sigma_{g}=\left(\frac{d_{84,1}}{d_{15,9}}\right)^{1 / 2} \\
& G=1 / 2\left(\frac{d_{84,1}}{d_{50}}+\frac{d_{50}}{d_{15,9}}\right)
\end{aligned}
$$

The $\sigma_{g}$ and $G$ values for the sediment characteristics which were used in the laboratory experiment according to the above equation are consecutively 1.4142 and 1.1415 .

\subsection{Experiment Running}

The procedures for executing the laboratory experiment are as follows:

a) The groundsill was placed in series.

b) The channel was watered in a certain amount of discharge and required time was recorded, in 
which for it to reach the balance on bed until no scouring happened again.

c) The observation was done on the scour depth near the downstream of the groundsill, as well as for the groundsill length and the scouring pattern.

d) Measuring the river bed elevation on a certain interval.

e) Analysis and interpretation of the research result.

Retrieval of the scour depth data when the streaming occurred (on a certain amount of discharge) was conducted for several times, until the condition where the scouring depth was no longer increased, so called the equilibrium condition.

\subsection{Experiment Result}

The laboratory experiment was conducted in the condition of scouring phenomenon with clear water scouring, in which the threshold height from the river bed of $0.5 \mathrm{~cm}$ did not cause sediment movement from the groundsill threshold, both the Groundsill Type I and Groundsill Type II. To provide the understanding of the investigation results, all parameters are presented in non-dimensional value. The dimensionless discharge was the ratio of measured flow discharge and reference discharge ( $q$-reference), while dimensionless scour depth and scour length were the ratio of the depth and scour length and river width. The reference discharge ( $q$-reference) was the lowest discharge from the running, which was about $4.69 \times 10^{-5} \mathrm{~m}^{3} /$ second or $2.816 \mathrm{l} / \mathrm{min}$.

The laboratory experiment was conducted with movable bed, with mean grain diameter $\left(d_{50}\right)$ of 0.83 $\mathrm{mm}$. Figure 7 shows that both in the Groundsill Type I and Groundsill Type II, maximum scour depth did not occur, even with large discharge. The higher flow discharge, the more severe scouring, yet optimum condition could be reached on certain discharge in which the increase of flow discharge no longer caused the increase of scour depth. In such condition, the scour depth was decreased in the vertical direction, yet increased in a longitudinal direction until reaching a point where the scouring is stopped (equilibrium). The bed materials were only spinning around in the scour area, and could not be entrained. When $q / q$-reference was less than 7, the maximum scours depth occurred at Groundsill Type I (without opening). At q/q-reference
$>7$, the maximum scours depth occurred in the Groundsill Type II, while at the wing section, it generally was the smallest one. These phenomena indicate that in a certain limit, the design of the Groundsill Type II needs to consider the hydraulic stability, particularly in the opening.

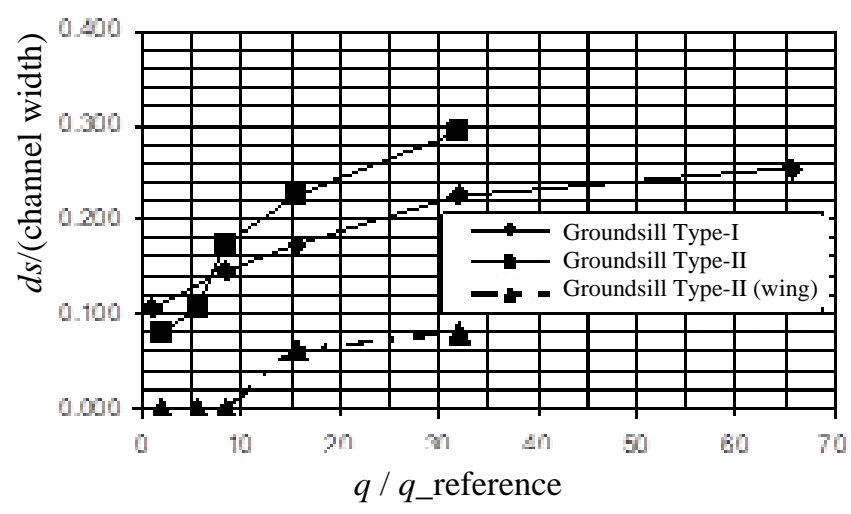

Figure 7. The relationship between the relative unit discharge (q/q-reference) and the relative scour depth (ds/channel width).

Scour depth was increased faster at the beginning of scouring. After a while, the increase rate of the scour depth was decreased until reaching an equilibrium condition. Figure 8, Figure 9, and Figure 10 show the increase rate of the scour depth within time on varied flow discharge for Groundsill Type I, Type II-opening type, and Type II-wing, consecutively. Generally, the increase rate of the scour depth was asymptotic against time.

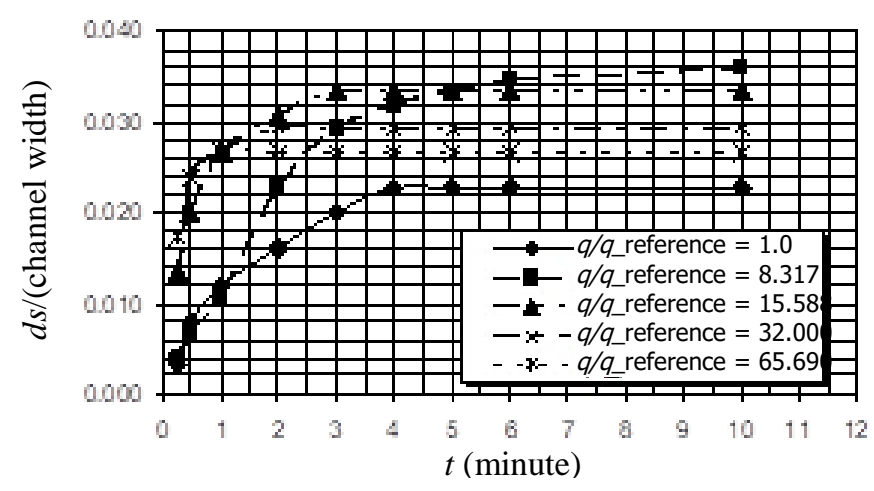

Figure 8. Time versus non-dimensional scour depth (Groundsill Type I). 


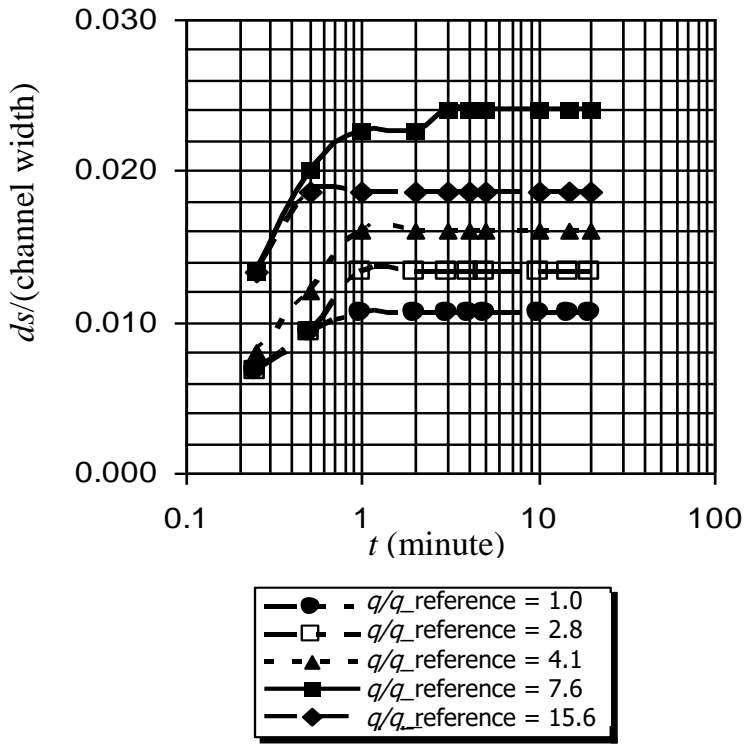

Figure 9. Time versus non-dimensional scour depth (Groundsill Type II-Opening type).

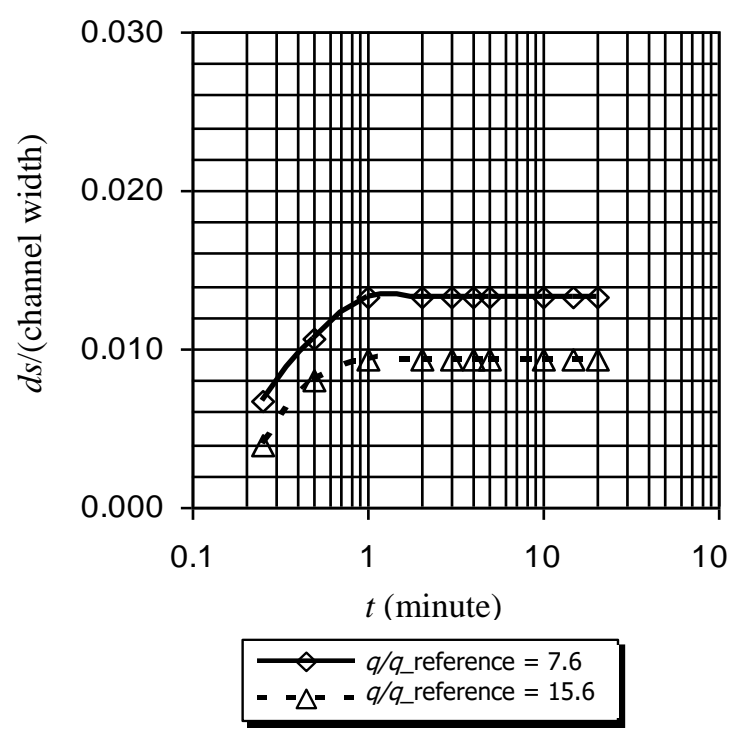

Figure 10. Time versus non-dimensional scour depth (Groundsill Type II-Wing).

The largest scour length on certain discharge generally happened in the Groundsill Type I on its opening type, followed by Groundsill Type I and then the wing section of the Groundsill Type II. On certain discharge (q/q-reference value $<10$ ), there was no scouring occurred on the downstream side of the wing section of the Groundsill Type II (see Figure 11). The scour length also could be influenced by the water level at the downstream of the groundsill. If the water level was relatively high, the scour length was smaller than low water level condition. In practice, the water level at the downstream may vary according to the presence of groundsill.

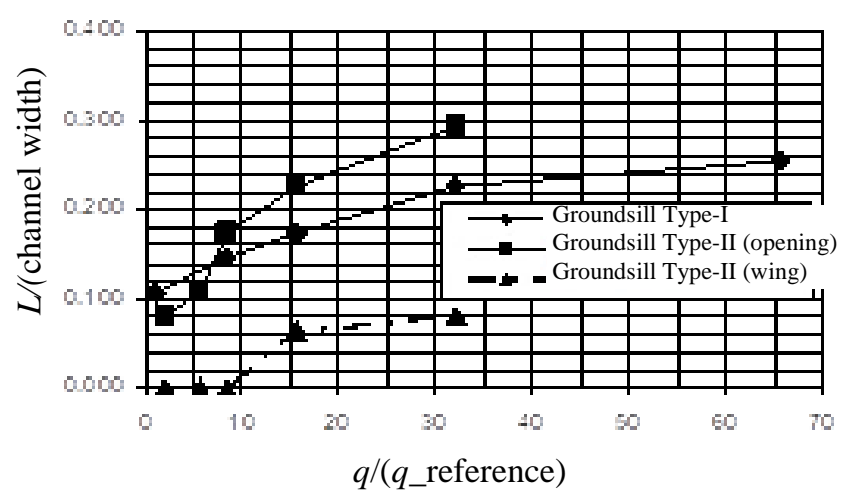

Figure 11. The relationship between the relative unit discharge ( $q / q$-reference) and the relative scour length (L/channel width).

\section{ANALYSIS AND DISCUSSION}

To assess the advantages of Groundsill Type II compared to the Groundsill Type I, the analysis and discussion (hydraulic) of both groundsill types are described as follows. The analysis comprises the relation between discharge and scour depth, the relation between time and scour depth, and the relation between discharge and the scour length.

\subsection{Relation between discharge and scour depth}

There was a discrepancy on scour depth between experiment results and theoretical analysis according to Equation (1). Equation (2) can be solved by considering sediment size parameters $\left(d_{50}\right)$, discharge per unit width $(q)$, cross section characteristic (geometry and $n$-Manning roughness coefficient), with value as follows,

a) $d_{50}($ from Figure 6$)=0.83 \mathrm{~mm}$

b) $q$ (discharge per unit width), according to ones applied in the laboratory

c) n-Manning $=0.032$

d) river width $=0.75 \mathrm{~m}$

e) $f=$ silt factor value, calculated with Equation (2) $=$ $1.76 \sqrt{d_{50}}=1.598$

The results of comparison between scouring analyzed theoretically and laboratory investigation for Groundsill Type I and Groundsill Type II were shown in Figure 12 and Figure 13, respectively. The scour depth value in the case of Groundsill Type I yielded from theoretical approach was initially lower than experiment results, particularly when the $q / q$-reference was less than 52 . While when the $q / q$-reference was larger than 52, the contrary happened. In the case of Groundsill Type II, at low discharge, the water would pass through the opening; therefore no scouring occurred at the downstream of the wing. The scour depth between theoretical approach and laboratory investigation indicated less conformity. This is 
understandable since it was difficult to model symmetric flow streamline. Thus, the flow discharge per unit width could not equally distribute, or on the other word, there was a concentrated stream.

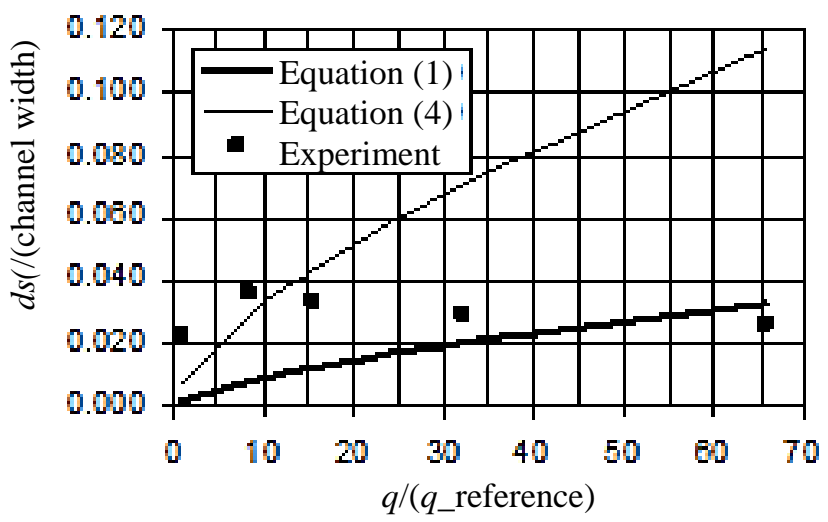

Figure 12. Scour depth versus flow discharge in the case of Groundsill Type I.

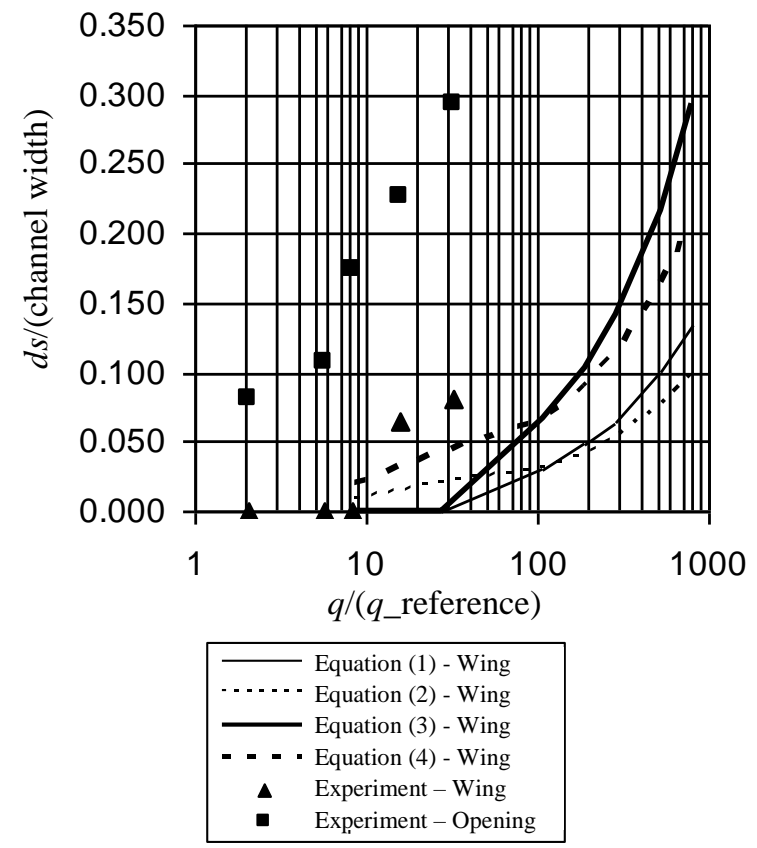

Figure 13. Scour depth versus flow discharge for Groundsill Type II.

\subsection{Relation between time and scour depth}

The scour depth was increased as a function of time. The increase rate of the depth was very rapid on the early time and gradually became constant. The flow velocity was still high enough to entrain the bed materials, then when the drag force was no longer strong enough due to low velocity, scouring on the bed was stopped. Changes in the flow discharge affected the changes of scour depth by time. This process would increase gradually, until at a condition in which the increase of space followed by the decrease of flow velocity could no longer exceed the critical shear stress.

\subsection{Relation between discharge and scour depth}

After running was conducted several times with 5 discharge variations for each groundsill types, it showed that the local scour depth occurred in the Groundsill Type I was relatively deeper and shorter compared to the opening Groundsill Type II, particularly at the opening section. The scour pattern occurred on the Groundsill Type I was distributed along the threshold since the flow velocity relatively distributed evenly along the threshold. For Groundsill Type II, the scour depth occurred (with the same discharge) on the wing section was relatively smaller than in the case of Groundsill Type I, and so do scour length. It was due to the higher flow velocity on the Groundsill Type II as the effect of concentrated on the opening. From the observation, it is found that the scouring pattern at near downstream of the groundsill was basically much narrower on groundsill with the opening. This may lead to the condition that the channel bank at near groundsill with opening is generally more stable.

The inconsistency between the scour depth obtained theoretically and experiment results were caused by two main points, i.e.:

a) The non-ideal flow behavior in which the flow streamline was not completely parallel or in the same direction with the main flow.

b) The sediment characteristic did not completely have a uniform size, as well as the grain which was not fully round.

Slightly different with Equation (2), the silt factor for the grain with diameter $0.83 \mathrm{~mm}$ (according to the linear interpolation shown in Table 1) was 1.598 , while according to the Equation (2), it was 1.603. The difference on the silt factor created a difference on the scour depth was considered insignificant, only about 2 $5 \%$. The difference on scour depth between experiment results and theoretical analysis was varied in the range of 22.17 to $91.17 \%$, and 19.98 to $328.47 \%$ for Groundsill Type I, respectively, according to Equation (1) and (4) (see Figure 12). Meanwhile, the difference on scour depth for the Groundsill Type II from experiment and theoretical analysis was difficult to conclude. However, in general, it could be stated that the scour depth equation of Blench was closer to the experiment analysis result (see Figure 13). Therefore, in terms of unavailable empirical study, the scour depth prediction according to Blench equation is more recommended than the Lacey equation. 


\section{CONCLUSIONS}

The following conclusions wrap up the research results:

a) The relative maximum scours depth occurred in the case of Groundsill Type I was 0.036, with the relative discharge of 8.32 . The relative maximum scours depth occurred on Groundsill Type II was of 0.024 at the opening, and 0.013 at the wing section, with the relative discharge of 15.60 .

b) The relative maximum scours length occurred on Groundsill Type I was 0.253 , with the relative discharge of 65.69. The relative maximum scours length occurred on Groundsill Type II was 0.293 at the opening, and 0.080 at the wing, with the relative discharge of 32.00 .

c) In general, it can be seen that the scour length in the case of Groundsill Type I is longer than on the Groundsill Type II (particularly on the opening) due to concentrated stream (narrowing on the channel) affected by the presence of the opening.

d) In terms of the environment, the scour depth occurred on Groundsill Type II was worthwhile since longer and deeper scour on the opening would create flow streamline on the river bed so that it allows the bed sediment transported to the downstream in low flow discharge.

\section{RECOMMENDATIONS}

The following recommendations are considered important for further studies:

a) It is necessary to study the effect of the scour depth against the variation of opening elevation, a variation of opening number, or variation of the characteristic of the river bed material.

b) The hydraulic stability of the groundsill structure made of different construction materials, such as massive construction, rock gabion is required. c) This laboratory study is still a qualitative finding to highlight the better performance of the groundsill with the opening rather than that of groundsill without the opening. Further experiments on the similar study should be conducted taking into account various real river courses and flow conditions.

\section{REFERENCES}

Hoffmans, G. J. C. M. \& Verheij, H. J., 1977. Scour Manual. Rotterdam: A.A. Balkema.

Elsebaie, I.H., 2009, “An Experimental Study of Local Scour Around Circular Bridge Pier in Sand Soil", International Journal of Civil \& Environmental Engineering IJCEE-IJENS, Vol: 13 No: 01.

Khwairakpam, P. and Mazumdar, A., 2009, "Local Scour Around Hydraulic Structures", International Journal of Recent Trends in Engineering, Vol. 1, No. 6, May 2009.

Neill, C., 1975. Guide to Bridge Hydraulics. Toronto: University of Toronto Press.

Novriska, R., 2000. Aplikasi Bangunan Pengendali Dasar (Groundsill) Berwawasan Lingkungan [Implementation of Environmentally Sound River Bed Control Structure (Groundsill)], Yogyakarta: Universitas Gadjah Mada.

Raudkivi, A. J., 1967. Loose Boundary Hydraulics, London: Pergamon Press Ltd.

Sosrodarsono, S., 1985. Perbaikan dan Pengaturan Sungai [River Restoration and Management]. Jakarta: Pt. Pradnya Paramita.

Vanoni, V. A., 1975. Sedimentation Engineering. American Society of Civil Engineering. 